\title{
Alarm device for self-tracking of progression during wrist rehabilitation
}

\author{
Mritha Ramalingam ${ }^{1}$, Elanchezhian Chinnavan², Nur Syamimi Binti Jasmi², Goh Mei Xin², Yuvaneswary Santhiresegar², \\ Rishikesavan Ragupathy ${ }^{2}$ \\ ${ }^{1}$ Corresponding Author, Faculty of Computer Systems \& Software Engineering, Universiti Malaysia Pahang, Malaysia \\ mritha88@gmail.com \\ ${ }^{2}$ School of Physiotherapy, Faculty of Allied Health Professions, AIMST University, Malaysia \\ chinnavanelanchezhian@gmail.com \\ n.syamimi1437@gmail.com \\ mykissshuffle@gmail.com \\ yuva_n@ymail.com \\ ptrishi@yahoo.co.in
}

\begin{abstract}
This study aims to design an alarming device for patients requiring wrist rehabilitation. Wrist injury due to accident, sports, stroke, and prolonged hand immobilization often requires physical therapy for rehabilitation to reduce pain, improve range of motion (ROM), and regain strength and function. Physical therapists use a goniometer to measure ROM. Although systematic treatment for wrist rehabilitation is physical therapy, current researchers are seeking an alternative and self-educative procedure based on engineering principles. This paper proposes a self-educative assessment and progress tracking design by exploiting an engineering design. This design is aided by a microcontroller, interfaced with sensors and display unit to measure wrist orientation of patients. The sensors measure the ROM of patients. This system uses a buzzer as an alarm tool for the patients during therapy. If the patients have achieved targeted movements, a beep sound would be produced to notify the patients. Thus, patients will be attentive in the treatment and motivated to proceed with the therapy. Visualization of the ROM through the display unit and alarm signal acts as an educating platform. The prototype was administered on 5 subjects with reduced ROM in wrist. Results showed that the proposed design increases ROM and self-educate the patients with wrist injuries $(\mathrm{p}<0.05)$.
\end{abstract}

\footnotetext{
Mritha Ramalingam et al. This is an open-access article distributed under the terms of the Creative Commons Attribution 3.0 United States License, which permits unrestricted use, distribution, and reproduction in any medium, provided the original author and source are credited.
}

\section{INTRODUCTION}

Human hands, specifically the wrist, play a crucial role in performing various activities in daily life (Daniela et al., 2015). Many daily activities pose hazards to wrist and hand postures. Generally, wrist disorders could be recovered by undergoing rehabilitation exercises. In physical therapy, wrist rehabilitation is required for patients with conditions such as wrist or hand injury caused by sports (Goyal et al., 2013) or working with computers, trauma or surgery, and stroke. For such patients, the decreased range of motion (ROM), flexion, and/or extension of wrist cannot be regained fully (Breitenseher \& Gaebler, 1997; Mirabello \& Andrews, 1992; Wiederhold \& Riva, 2012). Several exercises recommended in hand and wrist rehabilitation are flexion, extension, wrist rock stretch, ulnar deviation, radial deviation, pronation, and tendon glides (Vucekovich et al., 2005).

Proper hand rehabilitation is needed for vocational and functional restoration of hands that has been helpful in retraining hand function and decreasing the spasticity seen in stroke conditions. One of the major problems causing dysfunction of hand in stroke is spasticity. In most cases, when spasticity is severe, it develops deformity of the affected joints. Stroke rehabilitation, especially for the upper limbs in restoring the ability of daily living performance is possible with biofeedback techniques (Tahereh, 2015).

Universal goniometers are widely used by clinicians, particularly physical therapists, for measuring the ROM of the wrist. Visual analyses with universal goniometers as shown in Figure 1 are employed by individual therapists to observe the ROM on individual patients (Pham, 2015). Goniometer has played an important role in the history of 
medicine and rehabilitation for over 60 years. Nonetheless, several different methods are available for measuring ROM of different joints, from simple visual estimation to advanced high-speed technology.

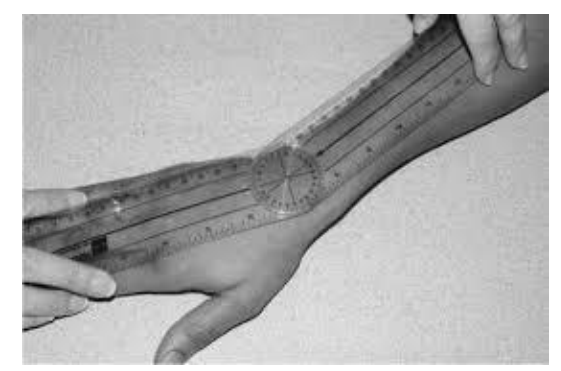

Figure 1. Goniometer used by therapist on individual subject

Rehabilitation is used to retrain the functional ability of hands with conditions such as muscle weakness, stiff joints, muscle tightness, and impaired coordination. All these conditions are usually seen in patients with arthritis, post fracture, soft tissue trauma, stroke, and nerve lesion. The outcome is measurable with increase in ROM in joint functions, improvement of hand muscle power, inhibition of hand flexor synergy pattern in movement, and better coordination of hand control. Currently, these symptoms are managed by joint manipulation, passive and active movements, passive stretching, Frenkel exercises, strengthening exercises, and biofeedback by therapist through ROM examination and motivation (Barreiro et al., 2003).

An electronic goniometer was designed to measure wrist/fingers force and movements at work, especially during typing, to prevent disorder of upper extremities (Gilsa \& Villaverde, 2011). In their design, with a sensor being fixed at the tip of the patients' finger, the patient is allowed to perform typing activity to record the forces that are exerted by the wrist and fingers. Then, the electronic goniometer is fixed at the metacarpal junction of the middle finger of the patients' hand. The electronic goniometer measures the reading of finger flexion and wrist movement along with force exerted. The results supported them to provide corrective measures to the patients to avoid further disorders.

Shakudo et al. (2011) employed different ways of improving adherence to exercise intervention. The authors proved that provision of regular feedback to participants in an exercise programme improved the outcomes. (Mestre \& Maiano, 2011).

However, the involvement of biomechanical method in rehabilitation allowed a more client-centered, holistic approach that facilitated the patient's adaptation, improved motivation and outlook, and provided clinically significant functional progress (Jada \& Rebecca, 2010). The controlled early mobilization showed encouraging results in children with tendon reconstruction (Moehrlen et al., 2009). This finding has motivated us to propose a self-educative device for progression monitoring of wrist rehabilitation to provide a platform that allow patients to perform wrist ROM exercises without over loading them.

The use of audio-visual feedback to induce cognitive training of the skill can significantly improve the performance (Zabala et al., 2009). In the current study, the proposed design aims to include visual stimulation and independent execution of exercises by patients.

An essential parameter for the evaluation of wrist rehabilitation is ROM. However, measuring ROM using a goniometer is inconvenient and sometimes unreliable (Lee et al., 2015). Researchers believe that the development of enhanced goniometers will improve wrist rehabilitation. Despite its advantage, goniometry is time consuming and demands proper training for patients. There is an abrupt increase in patient quantity which creates a big issue in the ratio of physical therapist and number of patients. Thus, a design based on modern technology is necessary to measure ROM accurately. Due to limited manpower for assistance in rehabilitation centers, the need for self-progress tracking tool is most desired.

Also, these type of assessments involve direct physical contact with the patient's hand, possibly leading to increased risk of infectious transmission for post-surgical conditions in patients. Fortunately, new goniometer models have been in used to assist therapists (Rome \& Cowieson, 1996). However, such measurements are limited by several constraints regarding reliability. To improve the reliability of ROM measurements, a better recording assessment design based on modern technology is necessary.

Nowadays, the health care devices are incorporating several engineering technologies (Puviarasi et al., 2018) such as microcontrollers, sensors, etc., in the design (Dryvendra et. al, 2015; Gurubaran et al., 2014; Kasilingam et al., 2014). Hence, the proposed work is a new design developed using several engineering technologies, such as microcontrollers, sensors, buzzer, and liquid crystal display (LCD), to assist in measuring ROM, track the progress, and alert the users. The proposed system is designed to assist wrist rehabilitation involving flexion, extension, radial, and ulnar deviation. This paper will describe the design features and the application of proposed self-tracking wrist rehabilitation device on real time patients with impaired wrist ROM.

\section{Methodology}

The proposed exercise programme using an alarm device for wrist rehabilitation is designed to focus on two psychological elements: education and motivation. Selfeducation: Before the treatment begins, the patient's initial 
hand ROM is recorded and patients are educated on this information. Motivation: While the patient is using this device, the patient will be encouraged to achieve further functional range. This is performed using a reminder in the LCD reading and buzzer alarm. This programme applies the reward theory to encourage patients to strive for improvement in their wrist movement rehabilitation and be independent while practicing wrist rehabilitation programme.

A mechanical device for progress tracking is designed using electrical buzzer, sensors, a LCD digital display screen, and a microcontroller. The main focus of this device was based on three key elements: visual, audio and proprioception that are specially designed for wrist rehabilitation. This device display the degrees of ROM when the patient is directed during rehabilitation exercises. A buzzer is attached to the device to alert the users. Also, the system allows the patient to pilot the hand movement on their own with a coordinated and guided track.

The block diagram of the proposed system is illustrated in Figure 2. The microcontroller acts as the main controlling unit of the proposed goniometer. The self-educative progressive wrist rehabilitation unit measures active ROM of flexion, extension, ulnar and radial deviations which are read by two sensors. Then, the sensor measurements are transferred to the microcontroller.

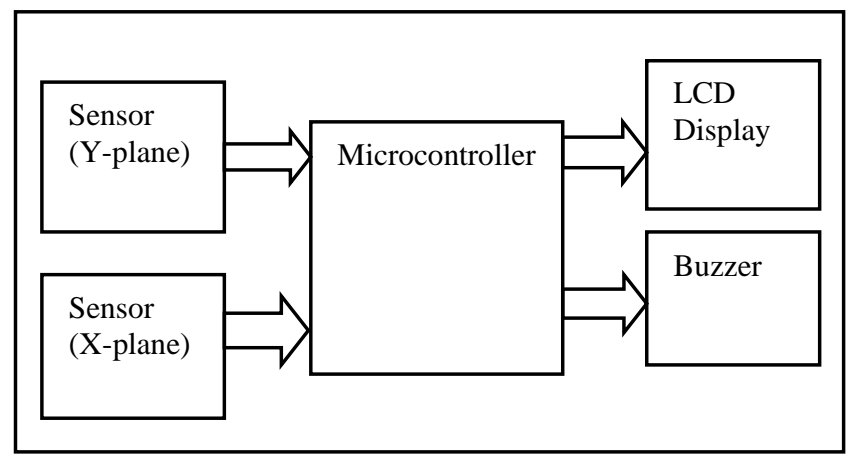

Figure 2. Block diagram of proposed self-tracking device

The microcontroller is programmed to display the measurements on the LCD. The LCD helps the patients to be aware of their progress during the rehabilitation. To selftrack patients' progress, the patients are alerted with an alarming signal, which is issued by the microcontroller through a buzzer.

\subsection{Microcontroller}

A microcontroller is a single-chip peripheral integrated circuit (PIC) computer. A PIC 16F877 chip is used in our proposed system. The PIC 16F877 has 40 pins, which are mostly software configurable for one of multiple functions (Lukman et al., 2016). The microcontroller processes all sensory measurements from the components and outputs the required data to the $\mathrm{LCD}$ display and buzzer.

\subsection{Sensors}

Hand movements and positions during wrist rehabilitation are determined by using position sensors. In this design, a potentiometer sensor is used, which is an inexpensive position sensor. The potentiometer sensor can be used for linear or angular (rotational) movements. As shown in Figure 3, in this biomedical application, two sensors were used to measure hand movement: one for vertical movement, y-axis ROM called as flexion and extension, and the other for horizontal movement, $\mathrm{x}$-axis ROM called as ulnar and radial deviation. When the potentiometer is used as a position sensor, the hand is placed directly on the angular shaft, which is a part of the potentiometer.

If the slider of the potentiometer is appropriately connected to the moving hand, then any movement in that hand will provide a direct measurement of position or change in position.

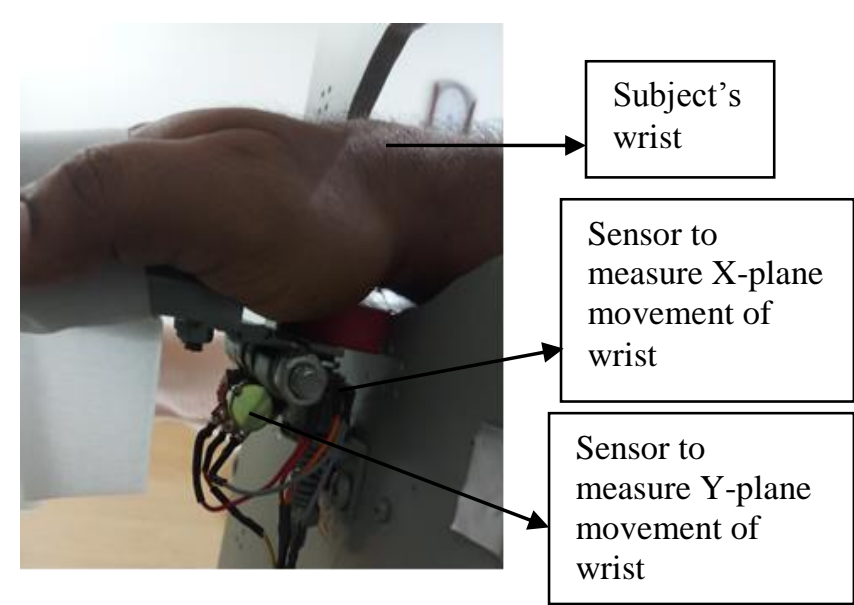

Figure 3. Proposed self-tracking device showing sensors for ROM measurement

\subsection{Buzzer}

A buzzer is an electrical device used for signaling. A typical use of buzzer include alarm devices and timers. A small electric buzzer could be interfaced with microcontroller, thus allowing current flow through the buzzer, resulting in the generation of a relatively sharp, single-tone frequency. A buzzer is used to provide acoustic feedback to patients. However, while working with bio-signals, a common requirement is the synchronization of recorded data with audio-capture devices. Based on the recorded ROM measurements, the microcontroller send signals to the buzzer, which can act as an alarm for the patients to track their rehabilitation progress. 


\subsection{Liquid Crystal Display}

The LCD that is utilized in the proposed design has a standard serial interface. A microcontroller needs to send two types of information for operating this LCD module, data information and command information. The interface between the LCD and the microcontroller can be 8 bits or 4 bits, and the difference between them depends on how the data or commands are send to LCD. The idea of 4-bit communication is introduced to save pins of a microcontroller. One may think that 4-bit mode will be slower than 8 bits, but the speed difference is only minimal.

The proposed progression tracking device is shown in Figure 4. The wrist goniometer was made of hard wood. The basement length and width were $55 \mathrm{~cm}$ and $25.5 \mathrm{~cm}$ respectively. The base was separated at the centre by a 40$\mathrm{cm}$ long wood to divide the forearm rest and wrist placement. The wrist rest plate was $18 \mathrm{~cm}$ in length and 8.5 $\mathrm{cm}$ in width. The wrist rest platform can move in vertical and horizontal direction: up and down (flexion and extension) and (right and left) for ulnar deviation and radial deviation.

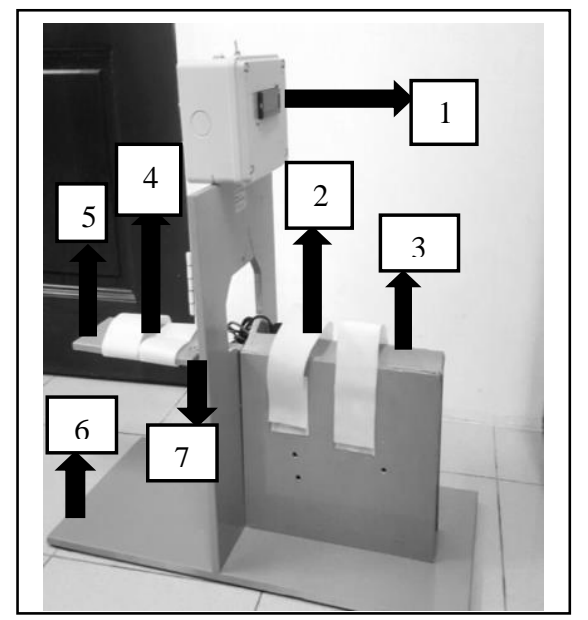

Figure 4. Proposed Self-tracking device

\section{Label No Label description of Figure 4}

1 Display of Sensor reading for ROM of wrist

2 Velcro straps for forearm stabilization

$3 \quad$ Forearm rest

$4 \quad$ Velcro strap for wrist stabilization

$5 \quad$ Wrist rest

6 Basement

$7 \quad$ Sensors
Velcro straps were installed at both wrist rest and forearm rest to avoid unnecessary movements and to maintain the stability of movement performance. The electronic parts were installed at the top of the wood in the central part for better viewing, so that patients could easily read the readings. The electronic parts are able to operate with direct electrical access. So the researcher must use electrical power to operate this device.

The ROM measurements of patients' wrist that are captured by the sensory circuits are transferred to the PIC microcontroller. The microcontroller is programmed to display the ROM values on the screen. The LCD is used to create patient awareness about their progress.

\subsection{Procedure}

This study was approved by research ethical committee, AIMST University. Written consent form, was obtained from the participants before the study. Subjects involved in the study were educated about the benefits and outcomes measures.

For this study, the participants were chosen with wrist movement's restriction who met the following inclusion criteria:

- Subject's age range between 20-40 years.

- Subject with wrist conditions such as muscle weakness, reduced ROM and post traumatic stiffness.

The study was conducted in some of the particularly chosen hospitals which has got the Physical therapy unit. Selfeducative progression tracking device was tested on 5 patients with reduced ROM on wrist. Both male and female were participated in the study. Both right and left wrist with reduced ROM subjects were recruited for the study.

The subjects were advised to visit the physiotherapy clinic five days in a week. The patients were made to sit comfortably on a chair of same height to the progression tracking device. The chair with adjustable height was suitable for individuals with different heights. The LCD was positioned at eye level for suitable viewing. Once the patient has his/her hand placed on the forearm and wrist rest, the forearm and hand were strapped for a better stabilization. When the patient was ready and comfortable, the researchers switched on the progression tracking device. In each session, the subjects performed active ROM by viewing the device for 20 minutes.

The ROM measurements of the patient are shown in Figures 5(a) and (b). At the resting position, the angle of wrist remains at $0^{\circ}$. 


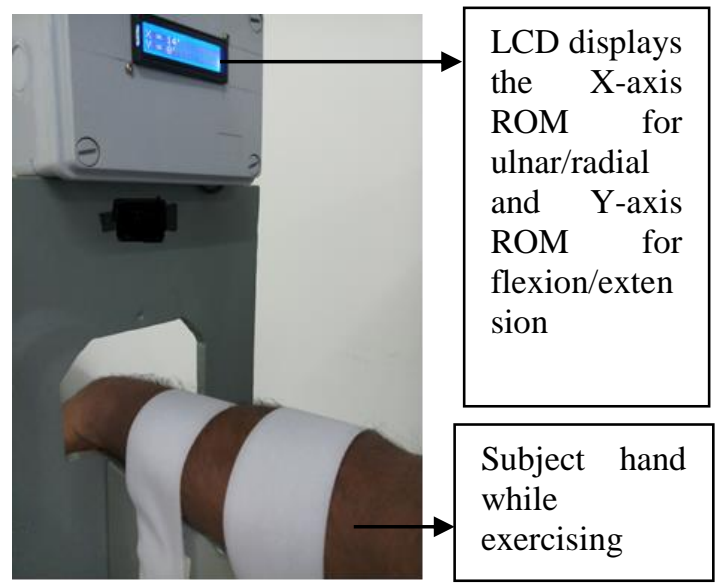

Figure 5. (a) ROM Measurement on LCD

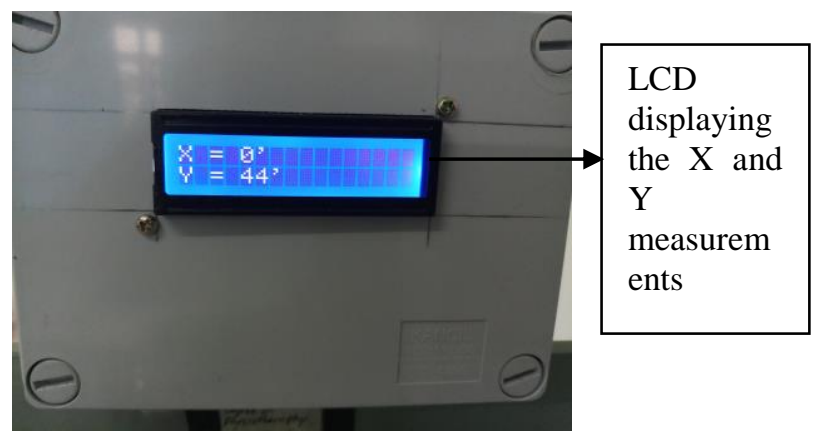

Figure 5. (b) ROM Measurement on LCD

The subject is advised by the physiotherapist to move the wrist to flexion and extension within their pain limit. This is displayed as Y-axis measurement in LCD as shown in Figure 5(b). The initial ROM is measured as displayed in the LCD. The subject is asked to repeat the wrist movement for 10 minutes. This acts a biofeedback to help the subject to increase the ROM. Now, the progression of wrist flexion and extension is measured as displayed in LCD with the help of sensor. Likewise, the wrist movement for ulnar and radial deviation is measured for 10 minutes using another sensor. The ulnar and radial movement are displayed as Xaxis measurement in LCD as shown in Figure 5.

The ROM of wrist joint was measured prior to study and after the study. Their measurements of initial and progression of fifth follow up were compared. This is shown in Table 1. The measured data are analyzed using the software, statistical package for the social sciences (SPSS) version 22 .

\begin{tabular}{l|l|l|l|l|l}
\hline $\begin{array}{l}\text { Wrist } \\
\text { Movement }\end{array}$ & Pre-test & Post test & $\begin{array}{l}\text { Paired } \\
\text { difference }\end{array}$ & t-value & $\begin{array}{l}\text { P - } \\
\text { value }\end{array}$ \\
\cline { 2 - 5 } & Mean \pm SD & Mean \pm SD & Mean \pm SD & & \\
\hline Flexion & $22.4 \pm 4.3$ & $32.6 \pm 3.7$ & $-10.2 \pm 2.8$ & -7.96 & 0.001 \\
\hline Extension & $20.2 \pm 4.5$ & $38.4 \pm 4.3$ & $-18.2 \pm 5.2$ & -7.80 & 0.001 \\
\hline $\begin{array}{l}\text { Radial } \\
\text { Deviation }\end{array}$ & $16.2 \pm 1.3$ & $32.0 \pm 2.1$ & $-15.8 \pm 1.9$ & -18.36 & 0.000 \\
\hline $\begin{array}{l}\text { Ulnar } \\
\text { Deviation }\end{array}$ & $18.4 \pm 2.7$ & $29 \pm 4.1$ & $-10.6 \pm 3.3$ & -6.42 & 0.002 \\
\hline
\end{tabular}

Table 1. Comparison of Pre and Post ROM in wrist joint

The effectiveness of proposed self-tracking device was assessed by subjects who were involved in the study by a self-evaluating questionnaire. The effectiveness of the proposed system are tabulated in Table 2. The results obtained from the patients based on the usage of this proposed system is shown in Figure 6.

\begin{tabular}{|c|c|c|c|}
\hline S.no & Item & $\begin{array}{l}\text { Chi- } \\
\text { Square }\end{array}$ & $\begin{array}{l}P \quad- \\
\text { value }\end{array}$ \\
\hline 1 & $\begin{array}{l}\text { Feeling comfortable in } \\
\text { using this device }\end{array}$ & \multirow{10}{*}{6.400} & \multirow{10}{*}{0.011} \\
\hline 2 & $\begin{array}{l}\text { Enjoy training with the } \\
\text { device }\end{array}$ & & \\
\hline 3 & $\begin{array}{l}\text { More attentive in hand } \\
\text { rehab programme }\end{array}$ & & \\
\hline 4 & $\begin{array}{l}\text { Feeling motivated in hand } \\
\text { rehabilitation }\end{array}$ & & \\
\hline 5 & $\begin{array}{l}\text { Helps in improving } \\
\text { achievable range of motion }\end{array}$ & & \\
\hline 6 & $\begin{array}{l}\text { Sense the improvement in } \\
\text { the coordination of wrist }\end{array}$ & & \\
\hline 7 & $\begin{array}{l}\text { Addition of visual cue } \\
\text { (angle reading) and audio } \\
\text { cue(buzzer) in this device }\end{array}$ & & \\
\hline 8 & $\begin{array}{l}\text { Improve your activity of } \\
\text { daily living }\end{array}$ & & \\
\hline 9 & $\begin{array}{l}\text { Sensing increased strength } \\
\text { in wrist after using this } \\
\text { device }\end{array}$ & & \\
\hline 10 & $\begin{array}{l}\text { Prefer using this device or } \\
\text { practice free exercises }\end{array}$ & & \\
\hline
\end{tabular}

Table 2. Effectiveness of Self-tracking device 


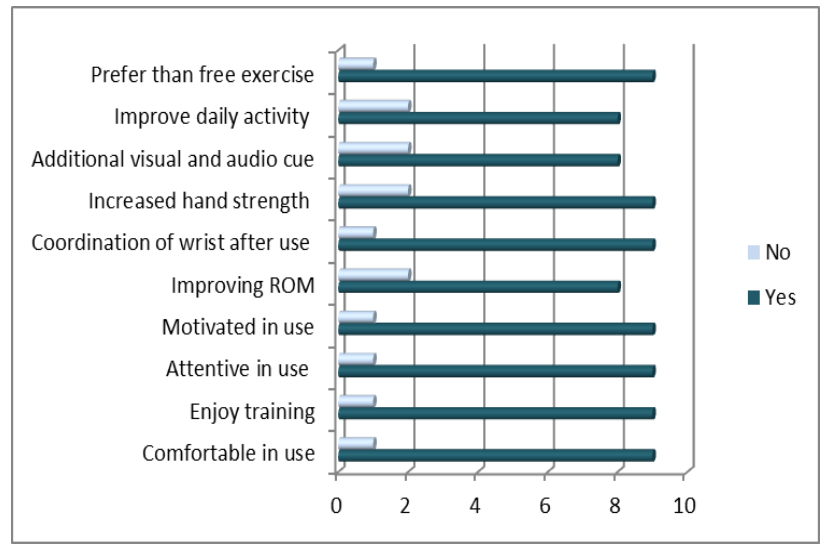

Figure 6. Implementation Results of Self-tracking device

While a patient is exercising, they might urge themselves to complete the exercise as quickly as possible for fast recovery. This might cause second injury or slow progress in patients' recovery process. The therapists set the rangelimit for exercise on the device according to patient's level of ability to perform the exercises. While the patient is involved in the rehabilitation, if the ROM value increases above the limit, then the buzzer will sound to alert the patients and therapists. Then the patients would proceed with the programme according to the suggestion provided by the therapist.

In conventional Goniometer, an individual subject is fully dependent on the physiotherapist throughout the course of rehabilitation to measure his/her ROM progression. But, in the proposed self-tracking device, an individual subject is independent to use the device as advised by physiotherapist. Also, the progression in wrist ROM is known to the subject instantly using a LCD display which acts as a motivation for the subject to improve his/her ROM to the maximum limit. So this self-tracking facility of our proposed device would be an assistive aid in today's rehabilitation programme.

\section{DISCUSSION}

The results show that the self-tracking device is significant ( $\mathrm{p}<0.05$ ) by comparing the pre and post values of ROM of wrist joint and also by the self assessing questionnaire used. The results are supported by Pham et al. (2015). Their study states that an accurate and standardized tool to measure the active ROM of the hand is essential to any progressive assessment scenario in hand therapy.

From this study, the researchers have recorded the improvement in patients' daily follow-up activities. Whenever the patient noticed their improvement, they automatically expressed their desire to improve more. The current study showed positive results in improving patient's motivation by using self-tracking process.
The findings showed that the self-educative progression tracking device positively affects wrist rehabilitation. Shakudo et al. (2011) stated that patient's adherence to an exercise programme with self-tracking improves the ROM and helps in achieving functional activities in their daily life.

Also, the self-educative progression tracking goniometer was designed to produce an alarm upon patient's improvement. The buzzer produces a beep sound if the patient has achieved a target range set by the therapist. This feedback allow patients to be attentive in the treatment and motivate them to perform better during the treatment. Zabala et al. (2009) showed that the external vocal commands "voice box" system supplemented by starting lights or buzzers can improve the performance or activity performed.

The wrist rehabilitation alarming device can provide measurement to track progression. This device could be helpful for physiotherapist as a tool to measure the range automatically instead of manual measurement, thus saving time and effort. Moreover, this system educate patients to track their improvements by themselves and be aware of their movement's progression.

\section{LIMITATIONS}

The study was conducted by recruiting five subjects only. Also, this current study was performed without involving the control group of samples.

\section{Conclusion}

A proper wrist function is undeniably important in the wellbeing of a person. Therefore, wrist rehabilitation is significant in restoring the hand functions, especially in wrist functional movements. Goniometers are widely used in clinical settings for measuring the ROM of the hand. A self-educative progression tracking device was designed in this paper to assist in restoring wrist mobility. Also, the system assist patients in retraining the proper coordination of wrist movement with its guided track. Moreover, it provides immediate feedback education to users to track their progressions. The proposed tracking device has shown beneficial effects in wrist rehabilitation. Nonetheless, further improvement is desired. This prototype can be applied on large samples with control group in future. Future studies based on the concept of the tracking device are highly encouraged to re-evaluate the effectiveness of the design in the rehabilitation on other joint involved with ailment and also by increased samples size.

\section{ACKNOWLEDGEMENT}

Authors thank Dr. Yu Chye Wah, Dean, Faculty of Allied Health Professions, AIMST University for his statistical expertise that greatly assisted the study. 


\section{REFERENCES}

Barreiro M, Frere A, Theodorio A \& Amate F. (2003). Goniometer based to computer. The 25th Annual International Conference of the IEEE Engineering in Medicine and Biology Society. 17-21.vol. 4, pp. 32903293.

Breitenseher M.J \& C. Gaebler, (1997). Trauma of the wrist. European Journal of Radiology, vol.25 no.2, pp.129 139.

Daniela D, F. Persia \& B. Siciliano, (2015). A Low-Cost Haptic System for Wrist Rehabilitation, IEEE International Conference on Information Reuse and Integration (IRI), San Francisco, CA, USA 13-15 Aug. 2015, pp.491-495.

Dryvendra, D., Ramalingam, M., Chinnavan, E., \& Puviarasi, P. (2015). A better engineering design: low cost assistance kit for manual wheelchair users with enhanced obstacle detection. Journal of Engineering and Technological Sciences, vol.47, no.4, pp.389-405.

Gilsa A.L.M \& A.J.B Villaverde, (2011). Design of an electronic instrumentation for measuring repetitive hand movements during computer use to help prevent work related upper extremity disorder. Elsevier. International Journal of Industrial Ergonomics, vol.41, pp.1-9.

Goyal, M., Kumar, Monga A \& M. Moitra,(2013). Effect of Wrist Manipulation \&Cyriax Physiotherapy Training on Pain \& Grip Strength in Lateral Epicondylitis Patients. Journal of Exercise Science and Physiotherapy, vol. 9, no.1, pp.17-22.

Gurubaran, G. K., \& Ramalingam, M. (2014). A Survey of Voice Aided Electronic Stick for Visually Impaired People. International Journal of Innovative Research in Advanced Engineering (IJIRAE) Volume, 1.

Jada J \&I Rebecca, (2010). Documenting Progress: Hand Therapy Treatment Shift from Biomechanical to Occupational Adaptation, American Journal of Occupational Therapy, vol. 64, pp. 82-87.

Kasilingam, G., Ramalingam, M., \&Sekar, C. (2014). A survey of light emitting diode (LED) display board. Indian Journal of Science and Technology, 7(2), 185-188.

Lee SH, C., Yoon, SG., Chung, HC., Kim, Y Kwak Y, H Park, et al.,(2015). Measurement of Shoulder Range of Motion in Patients with Adhesive Capsulitis Using a Kinect. PLoS ONE, vol.10, no.6.

Lukman A.A, J. Agajo, J. GanaKolo, M.A Adegboye\& Y. Yusuf, (2016). Learning of Embedded System Design, Simulation and Implementation: A Technical Approach. American Journal of Embedded Systems and Applications, vol. 3, no.3, pp. 35-42.

Mestre DR \& E. M. Maiano, (2011). Virtual reality and exercise: behavioral and psychological effects of visual feedback. Study in Health Technology and Informatics, vol.167, pp.122-7.
Mirabello S, Loeb .P, \& Andrews J, (1992). The wrist: field evaluation and treatment. Clinics in sports medicine, vol.11, no.1, pp.1-25.

Moehrlen, U., L. Mazzone., C. Bieli\& Weber, D,(2009). Early Mobilization after Flexor Tendon Repair in Children. European Journal of Pediatric Surgery, vol.19, no.2, pp. 83-86.

Pham T, N. P. H. Trinh \& P. Fay, (2015). A Non-Contact Measurement System for the Range of Motion of the Hand. Sensors, pp.18315-18333.

Puviarasi, R., Ramalingam, M., Chinnavan, E., \& Kalayan, A. (2018, February). Design of Intelligent Traffic Controlling System using RF Transponder. In 2018 Fourth International Conference on Advances in Electrical, Electronics, Information, Communication and Bio-Informatics (IEEE) pp. 1-5.

Rome, K. \& F Cowieson, (1996). A reliability study of the universal goniometer, fluid goniometer, and electrogoniometer for the measurement of ankle dorsiflexion. Foot \& Ankle International, vol.17, pp. 28-32.

Shakudo M, M. Takegami, A. Shibata, M. Kuzumaki, T. Higashi T, Y. Hayashino, Y. Suzukamo, S. Morita, M. Katsuki\& S. Fukuhara,(2011). Effect of feedback in promoting adherence to an exercise programme: a randomized controlled trial. Journal of Evaluation Clinical Practices, vol. 17, no.1, pp.7-11.

Tahereh H.A, H. Haghgoo, E. Pishyareh\& A. Biglarian, (2015). The Effect of Biofeedback Therapy on Hand Function and Daily Activities in Stroke Survivors. Zahedan Journal of Research in Medical Sciences, vol. 17, no. 10 .

Vucekovich K, G. Gallardo \& K. Fiala, (2005). Rehabilitation after Flexor Tendon Repair, Reconstruction, and Tenolysis, Hand Clinics, Elsevier saunders, vol.21, pp. 257-265.

Wiederhold B, \& G. Riva. (2012). Balance recovery through virtual stepping exercises using Kinect skeleton tracking: a follow up study with chronic stroke patients, Annual Review of Cybertherapy and Telemedicine 2012: Advanced Technologies in the Behavioral, Social and Neurosciences, IOS Press. Australian, 2008, Australian Institute of Health and Welfare, Arthritis and osteoporosis in Australia 2008. Canberra, vol.181, pp.108-112.

Zabala M, C., Sánchez-Muñoz, \& M, Mateo,(2009). Effects of the administration of feedback on performance of the Bmx cycling gate start. Journal of Sports Sci Med. Vol.1, no.8 (3), pp. 393-400. 


\section{BIOGRAPHIES}

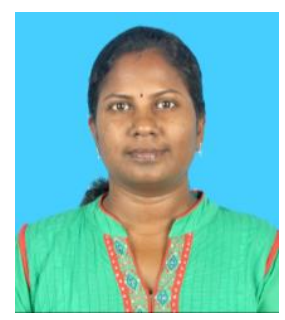

Mritha Ramalingam has received her B. Eng. and M. Eng. degrees in Computer Science and Engineering. She has received her Ph.D. in Computer Engineering. She is the Chartered Engineer in Engineering Council, UK. Her research interests include embedded systems, biomedical systems, steganography, cryptography, network security and computer networks.

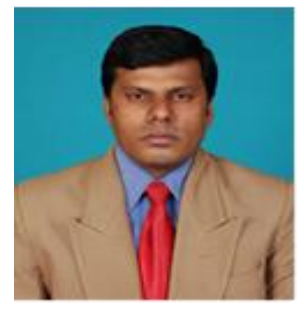

health care devices.
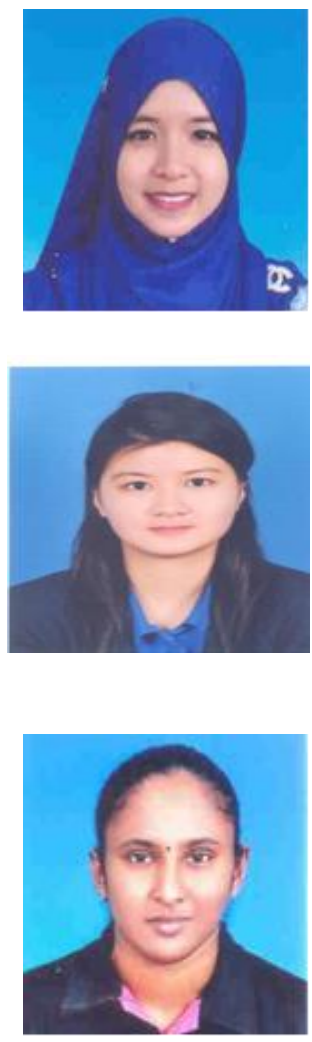

Yuvaneswary Santhiresegar has received her Bachelor of Physiotherapy (Hons) degree from AIMST University, Malaysia.

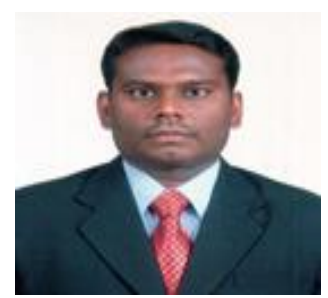

Rishikesavan Ragupathy has received his Master degree in physiotherapy specialization in sports physiotherapy from Tamilnadu Dr. M.G.R Medical University, India in 2003 and Post Graduate Diploma in sports
Goh Mei Xin has received her Bachelor of Physiotherapy (Hons) degree from AIMST University, Malaysia.

Elanchezhian Chinnavan has Physiotherapy specialized in Neurology. His research interests Musculoskeletal and Sports rehabilitation. $\mathrm{He}$ has passion towards design and modification of

Nur Syamimi Binti Jasmi has Physiotherapy (Hons) degree from AIMST University, Malaysia.
Management, (PGDSM) at Alagappa University, India in 2006. His research interests include sports fitness, musculoskeletal rehabilitation and innovation of devices in patients and sports persons care. 